1997 Particle Accelerator Conf., Vancouver, B.C., Canada,

\title{
MAGNETS FOR THE NATIONAL SPALLATION NEUTRON SOURCE ACCUMULATOR RING CONF.970.503-94
}

\author{
J. Tuozzolo*, J. Brodowski, G. Danby, J. Jackson, W. Meng \\ Brookhaven National Laboratory, Upton, New York 11973
}

RECEIVED

\section{Abstract}

The National Spallation Neutron Source Accumulator Ring ${ }^{1}$ will require large aperture dipole magnets, strong focusing quadrupole magnets, and smaller low field dipole, quadrupole, and sextupole correcting magnets. All of the magnets will provide a fixed magnetic field throughout the accumulator's fill/storage/extraction cycle. Similar fixed field magnets will also be provided for the beam transport systems. Because of the high intensity in the accumulator, the magnets must be designed with high tolerances for optimum field quality and for the high radiation environment which may be present at the injection/extraction areas, near the collimators, and near the target area. Field specifications and field plots are presented as well as planned fabrication methods and procedures, cooling system design, support, and installation.

\section{INTRODUCTION}

The performance requirements for the magnets have been defined and the magnet cross sections have been designed. Table 1 provides a listing of the DC magnets required for the ring, the high energy beam transport ${ }^{2}$ (HEBT) line from the Linac to the ring, and ring to target transport (RTBT) line from the ring to the target. Wherever possible magnets will be shared between the three different systems. The cross-sections for the major magnets are shown in figure 1.

\begin{tabular}{||l|c|c|c|c||}
\hline $\begin{array}{c}\text { MAGNET } \\
\text { TYPE }\end{array}$ & Location & $\begin{array}{c}\text { Aperture } \\
\text { x Length }\end{array}$ & $\begin{array}{c}\text { Field } \\
\text { kG }\end{array}$ & Qty. \\
\hline Dipole & Ring & $17 \times 45 \times 150$ & 7.1 & 32 \\
\hline Dipole & HEBT & $8 \times 30 \times 250$ & 3.0 & 13 \\
\hline Dipole & RTBT & $17 \times 45 \times 250$ & 7.1 & 1 \\
\hline Quad. & H\&L & $12 \times 50$ & 2.7 & 25 \\
\hline Quad. & Linac & $12 \times 50$ & 2.7 & 2 \\
\hline Quad. & R, H, RT & $20 \times 50$ & 3.4 & 77 \\
\hline L. Quad. & Ring & $30 \times 50$ & 4.5 & 8 \\
\hline VL. Quad. & RTBT & $36 \times 80$ & 3.6 & 2 \\
\hline Corrector & HEBT & $12 \times 12 \times 20$ & 0.3 & 27 \\
\hline Correctors & R, H, RT & $20 \times 20 \times 30$ & 0.2 & 77 \\
\hline
\end{tabular}

Table 1

*Work performed under the auspices of the U.S. Department of Energy.
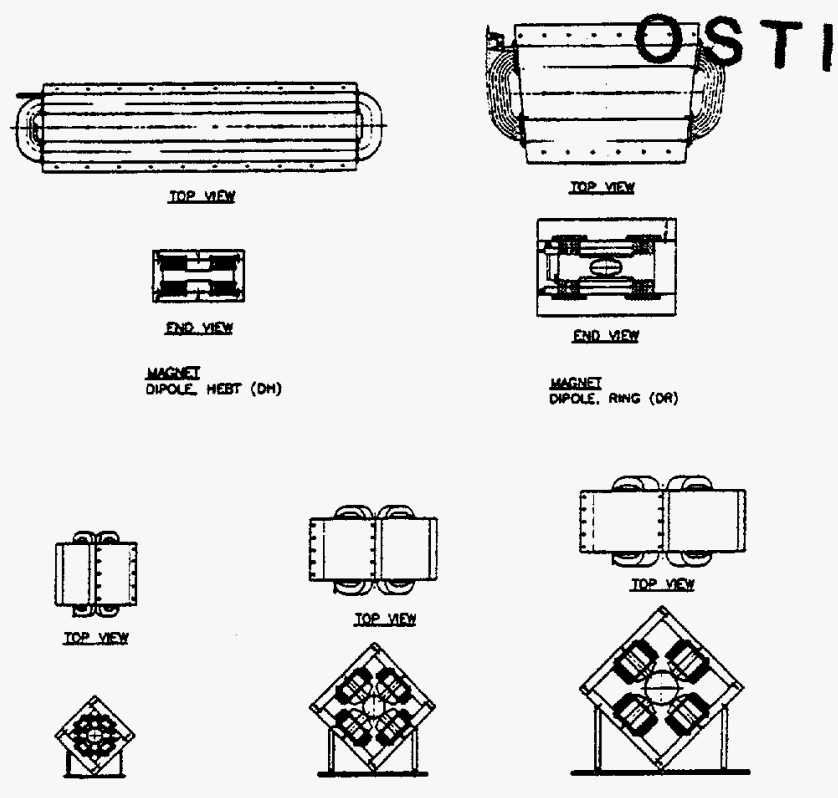

Exe vay

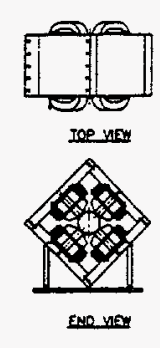

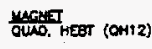

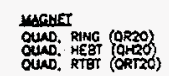

\section{JUN 251997}

Figure 1: Major Magnet Cross Sections

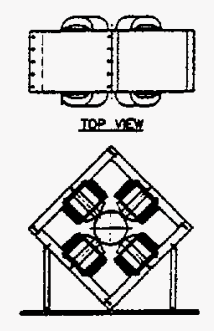

gap vay

Macaid

Preliminary studies of the magnetic field ${ }^{3}$ in the gaps have been completed. All of the magnets are conservatively designed to achieve the required field accuracy without expensive machining, special quality steel, or heat treating of the steel after fabrication. The magnet pole tips will have to be machined to a tolerance of $\pm .05 \mathrm{~mm}$. The mating pieces in the magnet must be within \pm .05 $\mathrm{mm}$. 1006 steel will be used throughout the core including the pole tips. Figures 2 and 3 are field plots for the ring dipole and standard ring $20 \mathrm{~cm}$. quadrapole.

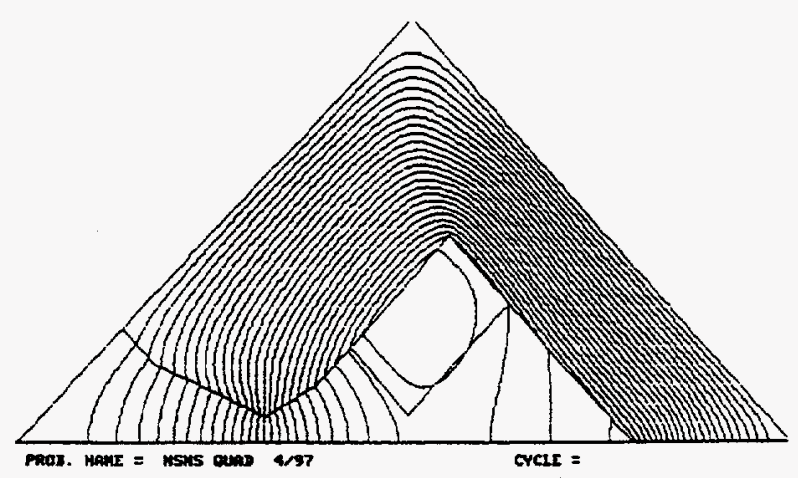

Figure 2: Ring $20 \mathrm{~cm}$ Quadrupole Field Plot 


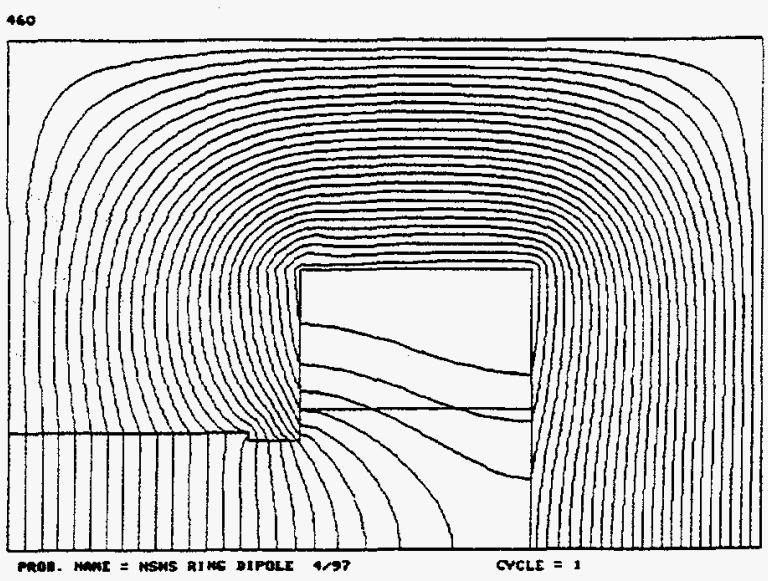

Figure 3: Ring Dipole Magnet Field Plot

\subsection{Magnet Core Design}

The magnetic cores must be accurate, inexpensive, reliable in a high radiation environment and easy to maintain. Low carbon steel cores manufactured from solid plate will meet these requirements. This method was used to fabricate the large core for the G-2 experiment superconducting magnet and is used throughout the AGS for the DC magnets used in the beam transfer lines. With computer numerically controlled machine tools the steel cores can be machined to high accuracy and repeatability. The solid cores are rigid requiring minimum stiffening from the support structure. The magnets will be built so they can be "split" for easy installation of the coils and vacuum chambers. This will allow the chambers to be built in separate clean rooms with no welding required after magnet assembly. The coils and heater blankets will also be accessible should they fail during initial testing.

For the small quantities required for the various sizes and shapes in the accumulator the solid core is significantly less expensive then a laminated core magnet. The RHIC injection transfer line magnets were built with $1.1 \times 10^{\sigma}$ lbs. of steel laminated cores which cost $\$ 2.75 / \mathrm{lb}$ in 1990. The G-2 ring which contains $1.6 \times 10^{6} \mathrm{lbs}$. of solid steel block of various sizes and shapes was built for $\$ 1.75 / \mathrm{lb}$ at the same time. The magnets in the accumulator rings and transfer lines will require $\sim 1.4 \times 10^{6} \mathrm{lbs}$. of steel.

\subsection{Magnet Coil Design}

The magnets will be designed with low current density (>350 amps $/ \mathrm{cm}^{2}$ ) copper coils wherever possible. The low current density will reduce the resistive energy loss in the coils and keep the voltage drop across the magnets low. This will reduce the possibility of turn to turn shorts occurring in the coil should the insulation be damaged by radiation. The low current density will also reduce the resistive heat loss in the magnet system. This will lower the power consumption of the accumulator and will reduce the load on the water cooling systems. All of the coils will have a single pass water cooling passage which will reduce the number of water fittings which can leak or fail to a minimum. The exception to this rule will be the high field quadrupoles. Space limitations at the ends require current densities of up to $450 \mathrm{amps} / \mathrm{cm}^{2}$ but these magnets will be sized for single pass coils.

The coils will use a modified epoxy/glass insulation which is used on AGS magnets in high radiation areas. Radiation protection will be provided by wrapping the coils with the glass tape which has a Kapton ${ }^{R}$ layer. Manufactured by August Krempel Co. Stuttgart, Germany, this material provides the radiation protection of Kapton ${ }^{R}$ with the bonding ability of glass fiber and epoxy. Because the manufacturing method for this insulating material is the same as a standard glass wrap insulation the increase in the coil costs will be small.

Magnesium Oxide mineral insulation has been used for very high radiation resistant coils in special areas ${ }^{4}$. The most common commercial use for this type of cable material is high temperature resistant heaters but it is sold with copper conductors. The coil material is expensive and it must be carefully formed with large radius bends to prevent damage to the insulation. The mineral insulating materials are very hydroscopic and will break down if exposed to humid air for extended lengths of time. The cable comes with a grounded metal cover which must be terminated with a brazed ceramic feedthrough to keep the coil insulation sealed. Because of the complexity of this type of coil it will only be used in areas where high dose rates are expected such as the last focusing magnets in the RTBT transfer line near the spallation target.

\section{THE CORRECTOR MAGNETS}

The corrector magnets are based on the new low field magnets used in both the AGS and the AGS Boosters. They will be air cooled window frame magnets. Kapton ${ }^{\mathrm{R}}$ coated wire will be wrapped around the steel leg of box or diamond shaped magnets. Each magnet will provide either horizontal or vertical dipole correction. In addition, the correctors in the accumulator ring will be wound to provide quadrapole, skew quadrapole, or sextupole correction.

\section{WATER COOLING REQUIREMENTS}

For radiation resistance and reliability, metal fittings and tubing will be used to carry the cooling water to and from the coils. The coil water lines will be mounted on insulated stand-offs and routed to a common water manifold on the magnet stand which will have an insulated ceramic break. The integrity of the water system will be monitored by klixon temperature sensors on each coil and flow switches on each of the return lines on the manifold.

All of the magnets will be cooled by the closed loop ring water system. This system will also provide cooling for the RF cavities, special injection magnets, and special extraction magnets. The water system will only see 
copper coils, copper cooling plates in the RF cavities, and stainless steel water pipe so corrosion in the system should not be a problem. The collimators and beam dumps which contain steel and much higher activation products will be on a separate systems. The pumps, heat exchangers, and other ancillary equipment for the ring water systems will be located in a separate water services building outside of the tunnels. Activated water from the ring will be kept in the tunnel or the service building during normal operation.

\section{MAGNET MEASUREMENT}

In addition to detailed field mapping of the first article magnets, all of the magnets built for the NSNS magnet systems be field tested after final assembly. This will serve as a final check on the quality of all aspects of the magnet assembly: the coils, the steel core, and the correct connection of the leads.

\section{STANDS AND INSTALLATION}

The magnets will be installed on the support frames outside of the accumulator ring. In the $90^{\circ}$ bends each large dipole bending magnet will be mounted with the corrector magnet and a quadrapole. In the straight areas the quadrapole will be mounted with a corrector magnet. This assembly will allow installation of a single vacuum chamber within all of the magnets without unnecessary flange joints. All of the magnets can be aligned on the support frame with the vacuum chamber and the associated beam position monitors outside of the ring. All of the magnets on an individual frame will be plumbed onto a single water manifold on the support frame, all of the coil heat sensors will be wired into a common wiring block, and the radiation monitors will be installed on the frame assembly as well. The completed frame assemblies with magnets and instrumentation can then be transported to the tunnel and moved around the tunnel to their final position using the tunnel crane. The frames will be placed on positioning jack stands and then surveyed into final position. All of the magnets for the Accumulator System will use similar frames for installation and support as shown in figure 4.

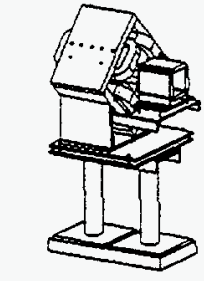

RING QUADRAPOLE AND CORRECTOR (OR30, CR3O)

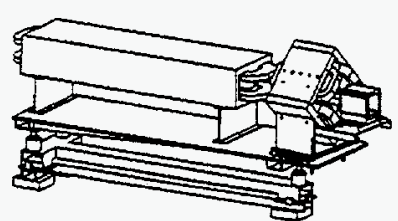

HEBT DIPOLE, OUADRAPOLE AND CORRECTOR

(DH8, $\mathrm{OH} 2 \mathrm{O}, \mathrm{CH} 2 \mathrm{O}$ )

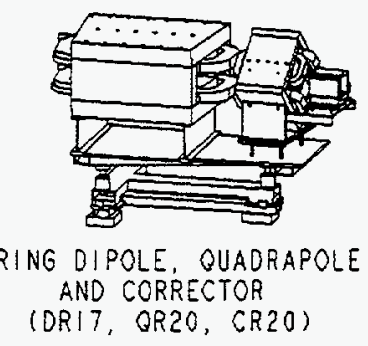

Figure 4. Magnets and Stand Assemblies

\section{CONCLUSIONS}

The magnets for the NSNS accumulator will be conservativily designed for reliability in a high radiation environment and ease of maintenance based on experience gained during the AGS Booster construction and upgrades to the AGS facility.

\section{ACKNOWLEDGEMENTS}

The authors would like to thank the design help of $R$. Ritter and $C$. Longo and the engineering help and advice provided by J. Cullen, C. Pearson, and A. Soukas.

\section{REFERENCES}

[1] W.T.Weng, et al, "Accumulator Ring Design for the NSNS Project", (these proceedings).

[2] D. Raparia, et al, 'The NSNS High Energy Beam Transport Line", (these proceedings).

[3] M.T. Menzel, "POISSON User's Guide", LAUR-87115, January 1987.

[4] "Moun g-2 Design Report", Brookhaven National Laboratory, AUI, Upton, NY 11973, AGS 821 July 1992.

[5] A. Harvey, "Radiation Hardened Magnets Using Mineral Insulated Conductors", LA-5306-MS, LANL, June 3, 1973

[6] C. Gardner, et al, "Analyis of Resonance Driven Imperfections in the AGS Booster", The $4^{\text {th }}$ European Accelerator Conf. 1994

\section{DISCLAIMER}

This report was prepared as an account of work sponsored by an agency of the United States Government. Neither the United States Government nor any agency thereof, nor any of their employees, makes any warranty, express or implied, or assumes any legal liability or responsibility for the accuracy, completeness, or usefulness of any information, apparatus, product, or process disclosed, or represents that its use would not infringe privately owned rights. Reference herein to any specific commercial product, process, or service by trade name, trademark, manufacturer, or otherwise does not necessarily constitute or imply its endorsement, recommendation, or favoring by the United States Government or any agency thereof. The views and opinions of authors expressed herein do not necessarily state or reflect those of the United States Government or any agency thereof. 


\section{DISCLAMMER}

Portions of this document may be illegible in electronic image products. Images are produced from the best available original document. 